\title{
Comparison of evacuation methods used in the Netherlands and the USACE Dam and Levee Safety Programs for the Natomas Basin (CA)
}

\author{
B. (Bas) Kolen ${ }^{1,2, a}$ \\ B. (Bob) Maaskant ${ }^{1}$ \\ S.N. (Sebastiaan) Jonkman ${ }^{3}$ \\ J.T. (Jason) Needham ${ }^{4}$ \\ ${ }^{1}$ HKV Consultants, Botter 11-29, 8232 JN Lelystad, Netherlands \\ ${ }^{2}$ Delft University of Technology, Delft Safety \& Security Institute, Mekelweg 2, 2628 CD Delft \\ ${ }^{3}$ Delft University of Technology, Mekelweg 2, 2628 CD Delft \\ ${ }^{4}$ US Army Corps of Engineers, 609 2nd Street, Davis, California
}

\begin{abstract}
Both in the USA and in the Netherlands, extensive studies on approaches for identifying flood risks (the combination of levee failure probabilities and consequences) are ongoing. A related topic concerns evacuation and emergency management (EEM). The magnitude of life loss is directly influenced by the effectiveness of EEM. Different models can be used to define the effectiveness of evacuation. The main objective of this study is to compare Dutch and American methods for evacuation as part of flood risk management strategies for a number of case studies in the US. A second, additional objective is to explore how approaches for EEM that have been recently developed in the Netherlands, can be applied in the United States. This research shows the benefits and limitations for the application of different types of models. This research contributes to the improvement of methods for emergency management, in the Netherlands, the US and other countries.
\end{abstract}

a Corresponding author: b.kolen@,hkv.nl, b.kolen@,tudelft.nl 


\section{Introduction}

Evacuation is a measure taken to potentially reduce the loss of life and damage to movable goods prior to arrival of a threat. Evacuation is a possible risk management strategy in response to the threat of flooding or hurricanes. Evacuation is defined as the process of alerting, warning, deciding, preparing, departing and (temporarily) holding people, animals, personal belongings and corporate stock and supplies from an unsafe location at a relatively safer location given the actual circumstances [1]. By evacuating, fewer people are exposed to the direct consequences of a disaster, provided that they can leave the area in time. If it is not possible to leave the area in time, people can reduce their vulnerability and risk of loss of life by moving to a relatively safe place such as a shelter or safe-haven.

Authorities can increase the effectiveness of an evacuation by offering specific information about the threat, detailing appropriate actions that should be taken by the at risk population. Authorities can also increase the effectiveness of evacuation by operational measures that influence the way infrastructure is used, for example by implementing traffic management closure of roads as the contra flow system in New Orleans,. Most areas have limited experience with evacuations due to the low frequency of severe floods and hurricanes. Therefore uncertainties are important to consider for emergency planning and crisis decision making.

The time required for evacuation depends on the characteristics of an area (e.g. the number of people, the capacity of infrastructure and the lead time prior to the flood or landfall of the hurricane) [2, 3]. If traffic congestion is limiting factor, the effectiveness of evacuation can increase when the existing traffic infrastructure is utilised more efficiently. For example, reduce cross-traffic on evacuation routes. Effectiveness can increase when measures (as warning and informing the public and operational measures) are implemented quickly and when routes are known by the evacuation population. When decisions to implement measures are made delayed, implementation becomes more difficult because of autonomous response of citizens and other operational services, logistical problems. In such a case measures can even be counterproductive because, during implementation, evacuation traffic can be delayed.

The effectiveness of an evacuation is influenced by four elements $[1,4]$ :

1. Threat and impact including the lead time and size of the (in this case flood) event

2. Citizens' response

3. Decisions made by the authorities

4. Environment and traffic infrastructure (demographics, infrastructure, buildings, capacity of emergency services).

The effectiveness can be described by the number of people that reach the planned destination, or the reduction of loss of life in case of exposure to the threat.
The process of evacuation can be divided in different phases. Literature [5] defines three phases which describe the process of evacuation started by a warning. :

- Departure: The combination of warning and mobilization which describes the number of people who start to travel as a function of time after a call for evacuation is made.

- Travel: The time needed to move from a place to another.

- Exit: The time needed to leave the evacuation zone.

Other literature [1] defines four phases which also take the requirements of the capacities of emergency services and infrastructure into account:

- Phase 0: Planning and design. Available plans, experience, efficiency infrastructure and risk perception can improve the success of evacuation.

- Phase 1: Detection and recognition (sense making) after early warning by decision makers and citizens

- Phase 2: Organization and decision-making by leaders and citizens (transition phase from normal life to an evacuation mode).

- Phase 3: Period of moving from one place to another including the process of warning and mobilization of the public after the evacuation decision has been made in phase 2 .

Recent research [6] specifies the process of evacuation between the detection of a threat and when protective action starts, they define:

- Warning delay time; the period between detection of a threat and when the warning is issued.

- Warning diffusion time; this period ends when the warning is received and is the start of 'departure' in the model of Van Zuilekom [5].

- Protective action initiation time; this period ends when people start to act, this is the start of phase 3 in the model of Kolen [1].

\section{Objective}

In this paper we focus on the time needed for removal of people out of the threatened area. This period includes the process of warning and mobilization after the threat is detected and information is made public by authorities or other media. Therefore we compare deterministic evacuations models that are used in the US (HECLifeSim) and in The Netherlands (Evacuation Calculator) and a probabilistic method EvacuAid.

Evacuation models can describe scenarios of evacuation. A scenario is defined as the consequences given a set of boundary conditions. Using deterministic scenarios and statistics about these scenarios, probabilistic analyses can be done.

Validation of the results of evacuation models is, in most cases, not possible because data for mass 
evacuations are limited [7]. Knowing where people were, when they received a notification to evacuate, how long they waiting before evacuating, and decisions they made regarding which route to take Other variables included are the uncertainty in the threat and (citizens') response during a subsequent event, the model itself. Also, organisational reasons have to be taken into account in case of low-frequency events. Because of the multiple involved organisations and many more emergency services, this will take time and will not be perfect. Ambiguity, or linguistic problems according to [8], that cause misunderstandings will influence the effectiveness of the chosen strategies.

However evacuation models can increase insight in the effectiveness of evacuation and be helpful to select the most effective measures for an area.

\section{Comparison of models}

In this section we describe the scope of the different models.

\subsection{General scope of the evacuation models}

\section{The Evacuation Calculator}

The Evacuation Calculator (see [5] for a detail description) can be used to assess the effectiveness of evacuation prior to a flood. This model is a macro model which is based on a static calculation using a departure curve, travel time and a potential delay at exit points. Different management strategies (optimistic, pessimistic and a reference) can be taken into account which give a bandwidth of the results. The model is used for planning and risk analyses in The Netherlands. The model describe the effectiveness in the number of people that can evacuate out of an area.

\section{HEC-LifeSim}

HEC-LifeSim (see [9] for a detail description) is a is a spatially-distributed, dynamic simulation model used to estimate potential life loss from flooding. It explicitly considers the primary factors influencing potential loss of life, including the warning and evacuation process, detailed flood dynamics, and loss of shelter. The warning and evacuation component, is an agent based (micro model) approach that simulates warning spreading through a community, how quickly people respond to that warning, and how the evacuation process plays out (including interaction of people and vehicles with the flood waters during an event). The model is not only useful for understanding potential loss of life from flooding, but also for analysing different evacuation approaches to help emergency managers develop or strengthen evacuation plans.

\section{EvacuAid}

This model (see [12] for a detail description) is a probabilistic models based on scenarios and statistics of them. EvacuAid compares different strategies for evacuation (as vertical and preventive evacuation) and presents the effectiveness of evacuation in the number of people that reach the planned destination as well as the expected loss of life. Until now EvacuAid is only applied using the Evacuation Calculator for evacuation prior to a flood.

\subsection{Comparison}

A comprehensive comparison of the various modelling approaches is included in table 1 . 


\begin{tabular}{|c|c|c|c|}
\hline & Evacuation Calculator & HEC-LifeSim & EvacuAid \\
\hline Population & People are related to zones & $\begin{array}{l}\text { People are defined as unique } \\
\text { avatars }\end{array}$ & $\begin{array}{l}\text { As used in deterministic model } \\
\text { that feeds EvacuAid }\end{array}$ \\
\hline $\begin{array}{l}\text { Evacuation application } \\
\text { / timing of evacuation }\end{array}$ & Prior to a flood & $\begin{array}{l}\text { Prior to flooding and during } \\
\text { flooding }\end{array}$ & $\begin{array}{l}\text { Prior to a flood for preventive } \\
\text { and vertical evacuation }\end{array}$ \\
\hline Safe locations & $\begin{array}{l}\text { Exit point in network or in a } \\
\text { shelter fraction }\end{array}$ & User defined & $\begin{array}{l}\text { Different location with unique } \\
\text { mortality rate for each location }\end{array}$ \\
\hline Transport of network & $\begin{array}{l}\text { Average travel speed and outflow } \\
\text { reduction factor using road } \\
\text { network }\end{array}$ & $\begin{array}{l}\text { Walking or driving over } \\
\text { transportation network with } \\
\text { actual road characteristics (\# } \\
\text { lanes, speed limit, direction, etc) } \\
\text { taken into consideration }\end{array}$ & $\begin{array}{l}\text { Preventive (by road network) and } \\
\text { vertical evacuation (walking and } \\
\text { road network) based on } \\
\text { deterministic models. The model } \\
\text { takes the probability of failure of } \\
\text { the network into account. }\end{array}$ \\
\hline Route choice & $\begin{array}{l}4 \text { different possible algorithms } \\
\text { (pessimistic, reference, } \\
\text { optimistic and user defined) }\end{array}$ & $\begin{array}{l}\text { Shortest time to safe location, } \\
\text { people can reroute when } \\
\text { confronted with a flood or traffic } \\
\text { jam }\end{array}$ & $\begin{array}{l}\text { Combination of used } \\
\text { deterministic scenarios, the } \\
\text { probability of these scenarios and } \\
\text { measures related to evacuation }\end{array}$ \\
\hline $\begin{array}{l}\text { Departure curve (time } \\
\text { between a warning and } \\
\text { protactive action) }\end{array}$ & $\begin{array}{l}\text { Pre-defined combining warning } \\
\text { and mobilisation }\end{array}$ & $\begin{array}{l}\text { Combination of warning } \\
\text { mobilization, } \\
\text { warning }\end{array}$ & $\begin{array}{l}\text { Combination of } \\
\text { deterministic scenarios, the } \\
\text { probability of these scenarios and } \\
\text { measures related to evacuation }\end{array}$ \\
\hline Calculation time & Minutes & Minutes & Hours \\
\hline
\end{tabular}

Table 1. comprehensive comparison of evacuation models.

\section{Case study: application of Evacuation Calculator and EvacuAid to Natomas Basin}

\subsection{Natomas Basin}

The Natomas Basin is a low-lying area of approximately $222 \mathrm{~km} 2$ that is situated in SacramentoSan Joaquin Delta in California. This area is surrounded by $69 \mathrm{~km}$ of levees, which reduces the potential from flooding at the western boundary from the hazard of Sacramento River and at the southern boundary from the American River. Three canals bound the area at the North, the Natomas Cross Canal (NCC), and the West, the Natomas East Main Drainage Canal (NEMDC), Pleasant Grove Creek Canal (PGCC). The levee system of Natomas Basin is designed to meet the 200-year flood protection level. The area is relatively flat with an elevation ranging approximately between 3 to 12 meter above mean sea level, where it should be noticed that the surface elevation of the adjacent land to the levee is lower than the water surface level of the Sacramento and American River [13]. The 100-year floodplain of the rivers and local drainage systems covers the entire area of Natomas Basin [13]. See [14] for a more detailed description of Natomas and the analyses.

\subsection{Evacuation Calculator}

The evacuation calculator is used to define the required time for evacuation in case of a preventive evacuation when people leave the area and vertical evacuation when people stay in the area. Non-response is taken into account, which means that some people will not follow the identified strategy (For example, when told to stay home, some people will use the road network to evacuate anyway.)

The population data is based on the Census Group Blocks 2010 of Sacramento County and Sutter County. The area of Sacramento is divided into 53 blocks (in total 99,480 persons9). 4652 persons is the maximum number of people in a block. Sutter County (1000 persons) is represented as one block. The road network of Natomas is used to develop the static model. Exit points are defined at the border of the Natomas area. When evacuees pass these exits they are assumed to be safe, however they need to travel on to a place to find shelter. Because of bottle necks and congestion on the network outside the Natomas area an outflow reduction factor is taken into account in the model. The centroid of each zone is connected to the centroid of the nearest link of a road. The people in a zone will enter the road network at this location. Figure 1 shows the capacity of the exit points which is taken into account. The exit points, blocks and road network is shown in figure 1.

For the Natomas Basin the population has grown from about 40,000 people in the year 2000 to almost 100,000 people in 2014. Depending on the scenario, the life loss has increased by a factor 2.5 to 3 . It is expected that required evacuation times will also increase with continued population growth. 

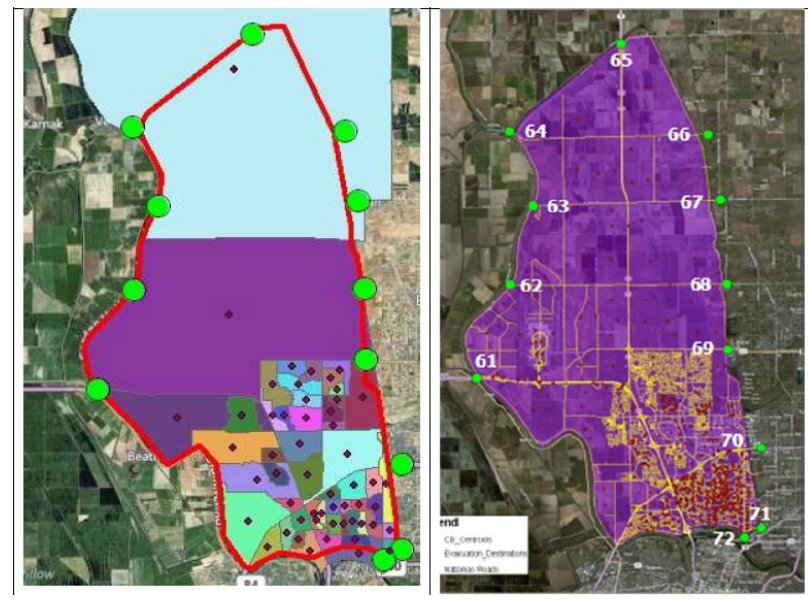

Figure 1: Left - Census group blocks in Natomas area and exit points (green dots). Right - road network.

\begin{tabular}{|l|l|l|l|}
\hline Centroid & Name & $\begin{array}{l}\text { Free flow } \\
\text { speed (miles } \\
\text { per hour) }\end{array}$ & $\begin{array}{l}\text { Capacity } \\
\text { (vehicles per } \\
\text { hour) }\end{array}$ \\
\hline 61 & I 5 NB & 65 & 6400 \\
\hline 62 & W Elverta RD & 50 & 1600 \\
\hline 63 & Riego RD & 50 & 1600 \\
\hline 64 & Garden HWY & 50 & 1500 \\
\hline 65 & HWY 99 NB & 50 & 1500 \\
\hline 66 & Sankey RD & 50 & 1500 \\
\hline 67 & Riego RD & 50 & 1600 \\
\hline 68 & W Elkhorn RD & 50 & 1600 \\
\hline 69 & $\begin{array}{l}\text { W Elkhorn } \\
\text { BLVD }\end{array}$ & 50 & 1500 \\
\hline 70 & I 80 EB & 50 & 6900 \\
\hline 71 & $\begin{array}{l}\text { Arden Garden } \\
\text { Connector }\end{array}$ & 50 & 3200 \\
\hline 72 & $\begin{array}{l}\text { Northgate } \\
\text { BLVD }\end{array}$ & 50 & 1500 \\
\hline
\end{tabular}

Table 2. Road capacities.

The western exits 62, 63 and 64 are not taken into account. These exits are located on the river levee and therefore cannot be considered as safe evacuation destinations. The following parameter settings were applied after discussion between NL en US experts to calculate evacuation times:

1. Non-response:

a. Preventive horizontal evacuation: $10 \%$ of the population stays at home in the Natomas area

b. Vertical evacuation: $90 \%$ of the population stays at home in the Natomas area

2. Departure Curve (DC): after 4 hours all inhabitants have left their homes and started to evacuate (except for the proportion nonresponse). Figure 2 shows the relation between the warning and mobilization as used by USACE.

3. Persons per vehicle (PAE): on average there are 3 persons in one vehicle

4. Speed: vehicles travel with $12.5 \mathrm{mph}(=20 \mathrm{~km} / \mathrm{h})$

5. Out flow factor: 0.2 , i.e., road capacities on the exit points are $20 \%$ of the free flow capacity due to congestion.

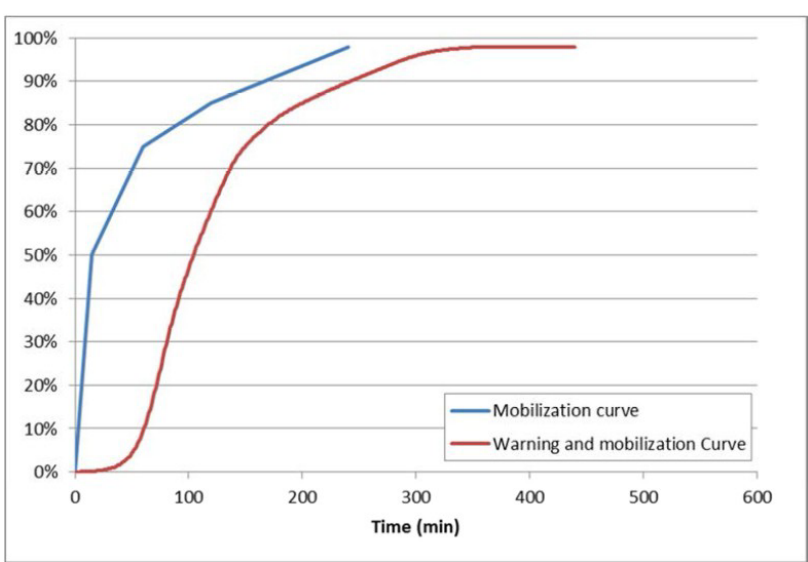

Figure 2: Warning and mobilisation curve as used by USACE

Figure 3 presents the results of the simulations. The figure compares the time needed for a preventive and a vertical evacuation. The figure also shows three management strategies:

- Nearest exit: all people leave Natomas Basin by the nearest exit

- Reference: inhabitants are assumed to be free in choice regarding their route for evacuation

- Traffic Management: traffic is spread over the network so the exit points are used optimal.
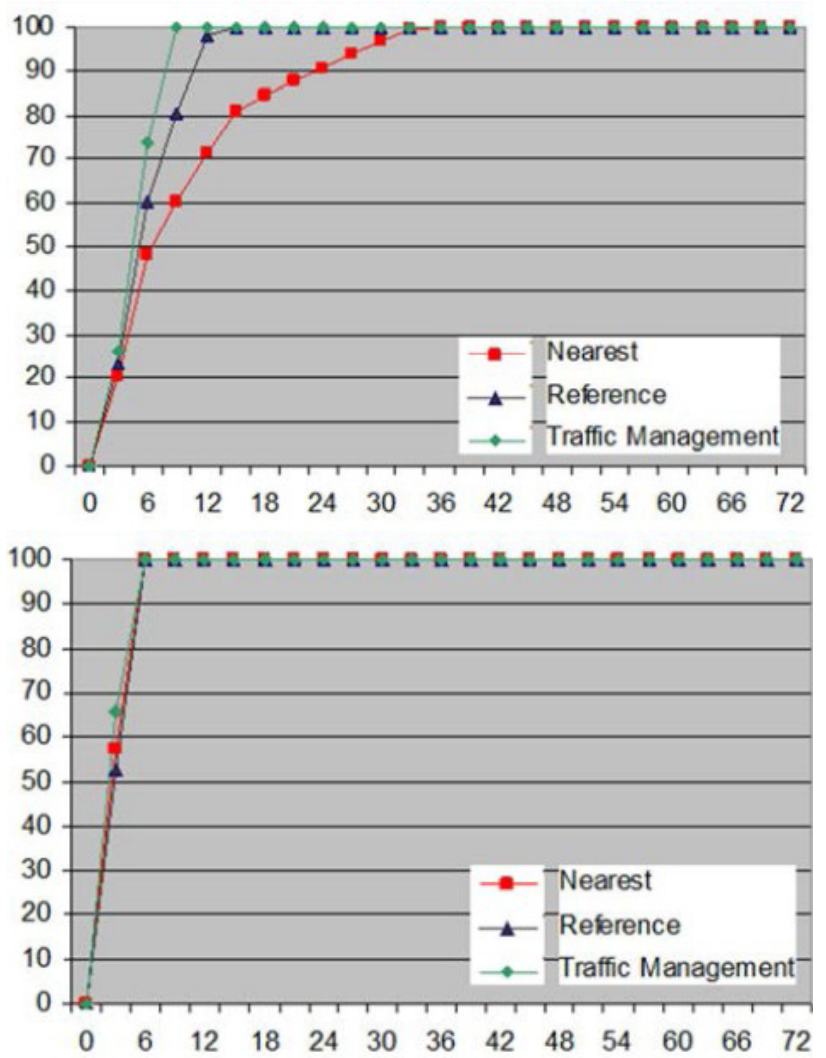

Figure 3 preventive evacuation (upper figure) and vertical evacuation (lower figure) with on the horizontal axes the time in hours needed for evacuation and on the vertical axes the percentage of people that has been evacuated defined by the Evacuation Calculator. 
The difference between the travel time in these strategies is an additional load on the road network equal to $80 \%$ of the population. In case of a vertical evacuation strategy congestion during the travel is so limited that the time needed for evacuation is almost equal to the departure curve, despite the strategy for evacuation. In case of a preventive evacuation the level of management matters as can be seen by comparing different strategies for evacuation. When people use the nearest exit some exits are heavily used (and overloaded) while other are not used. Traffic management which divides cars over the exits taking the capacity into account shows the upper limit.

Varying the parameter settings for the different input parameters provides insight in the range of the time needed for evacuation resulting from either more pessimistic or more optimistic assumptions. Table 3 gives the parameter settings that were applied to calculate the variations in evacuation times (nine variations). In every run only one parameter is changed. Figure 4 shows the results for the strategy reference in case of preventive evacuation.

\begin{tabular}{|c|c|c|c|}
\hline Parameter & Reference & \multicolumn{2}{|c|}{ Sensitivity analyses } \\
\hline $\begin{array}{l}\text { Departure } \\
\text { Curve }\end{array}$ & $\begin{array}{l}4 \mathrm{hr} \text { for } 100 \% \\
\text { departure }\end{array}$ & $\begin{array}{l}8 \mathrm{hr} \text { for } 100 \\
\text { departure } \\
\text { (DC) }\end{array}$ & \\
\hline $\begin{array}{l}\text { Persons per } \\
\text { vehicle }\end{array}$ & 3 & 2 (PAE2) & 4 (PAE4) \\
\hline $\begin{array}{l}\text { Non } \\
\text { response }\end{array}$ & $10 \%$ & $0 \%(\mathrm{NR})$ & \\
\hline $\begin{array}{l}\text { Driving } \\
\text { Speed }\end{array}$ & $12.5 \mathrm{mph}$ & $\begin{array}{l}5 \quad \mathrm{mph} \\
(\mathrm{V} 5 \mathrm{mph})\end{array}$ & $\begin{array}{l}20 \quad \mathrm{mph} \\
(\mathrm{V} 20 \mathrm{mph})\end{array}$ \\
\hline $\begin{array}{l}\text { Unavailable } \\
\text { exits }\end{array}$ & 0 & $\begin{array}{l}\text { Most } \\
\text { important exit } \\
\text { not available } \\
\left(\text { Exit } 1^{\text {St }}\right)\end{array}$ & $\begin{array}{l}\text { Second most } \\
\text { important exit } \\
\text { not available } \\
\left(\text { Exit } 2^{\text {nd }}\right)\end{array}$ \\
\hline $\begin{array}{l}\text { Congestion } \\
\text { at outflow }\end{array}$ & 0.2 & 0,1 (OF1) & 0.3 (OF3) \\
\hline
\end{tabular}

Table 3. Sensitivity analyses

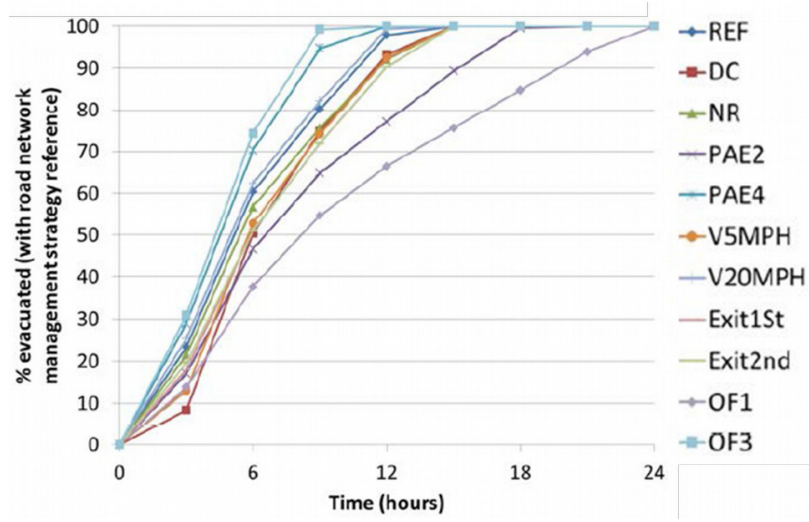

Figure 4: preventive evacuation

The results also show the importance of the element time. Given the steep slopes of the curves, a few hours less available will reduce the evacuation effectiveness far more than the parameters in the sensitivity analyses. For Natomas it is shown that all parameters related to the traffic load (as the number of people in a car, and therefore also the number of people in the area) as well as the outflow factor are more sensitive parameters. Applying the Evacuation Calculator the departure curve is shown not to be very sensitive for the time needed to evacuate all people, but in the first hours of the evacuation more people can evacuate out because of better use of the available road capacity (see figure 5). Therefore it is important to warn and mobilize people quickly. When time is limited the warning and mobilization can increase the effectiveness of vertical evacuation and citizen's response and therefore reduce loss of life.

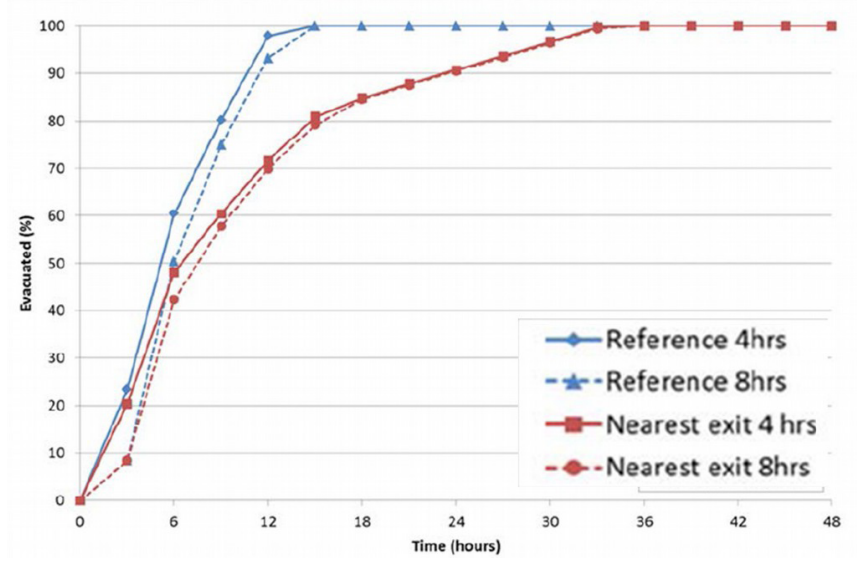

Figure 5: Effectiveness of evacuation using a departure curve of 4 and 8 hours in case of preventive evacuation.

\subsection{EvacuAid}

The model in EvacuAid has been developed using scenarios of the Evacuation Calculator. In this case study we applied equal probabilities for all scenarios as in The Netherlands (see [12) which are based on a Delphi approach and available statistics. To be used in real practice for Natomas Basin the probabilities have to be based on (local) experts. Because the time needed for vertical evacuation is limited, and the travel time for those who still evacuate preventive (the non-response group) is equal to the departure curve, the expected number of people that can evacuate out of the area is only shown for the strategy preventive evacuation.

Taken all scenarios and the probability of them into account the expected value for the evacuation time is presented in figure 6 . This figures presents the results for the different management strategies nearest exit, reference and traffic management as well as the expected value which combines all. Taking all scenarios into account also a bandwidth is presented indicated by the dotted line. 


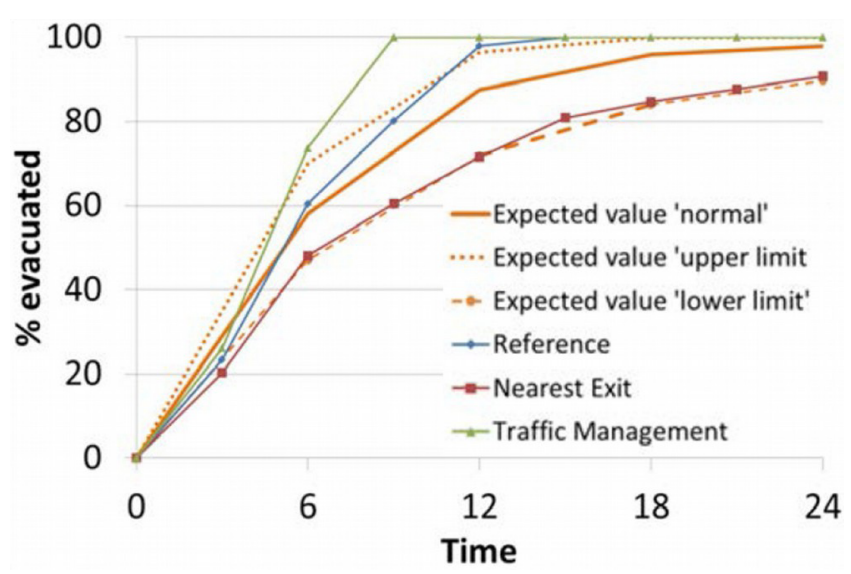

Figure 6: Results of EvacuAid

EvacuAid can also be used to estimate the expected loss of life in case of preventive and vertical evacuation taking mortality rates for different locations into account. Using the mortality functions of New Orleans (see [13]) we defined mortality functions for the different locations of EvacuAid by increasing or decreasing the function by a factor. For people which are not prepared and at home we used a factor 1 , at home and prepared as factor 0.2 , a factor of 0.1 for those in a shelter and a factor 5 for people exposed while walking or in a car during evacuation. A remark has to be made with regard of the recent developments since 2000 in Natomas, most of rooftops are now below the expected water level after a flood. In case of vertical evacuation people have to gather at central places or dry floors in existing buildings to hide for the flood. Still they face a risk for loss of life, but the risk can be less than for those who are exposed to a flood during evacuation in their car of when walking. In case of limited lead time (which depends on the relation between the required time for evacuation and the available time for evacuation) vertical evacuation can result in less loss of life than preventive evacuation. We suggest to do more research about the possibilities for vertical evacuation taken into account the expected conditions of buildings. .

\subsection{HEC-LifeSim}

HEC-LifeSim was also applied to the Natomas situation to simulate the evacuation process and develop estimates of how long it would take to evacuate the area. LifeSim used a standard approach where people attempt to evacuate following their perceived fastest route out of the area. This perceived fastest route is based on their understanding of the road network (number of lanes, speed limits, etc.), and which route would get them to one of the identified safe locations in the shortest amount of time. Their initial route selection has no understanding of possible congestion. However, upon entering a traffic jam, a proportion of the vehicles will attempt to reroute using the next best shortest time route rather than staying in the traffic jam. Results of the HEC-LifeSim analysis are shown in Figure 7.

Results show that if all destinations are open, the maximum time people would take to drive out of the area (from the time they depart their structure to when they reach a safe location) would be about 25 minutes. This time is based on the difference between the two curves in figure 7 .

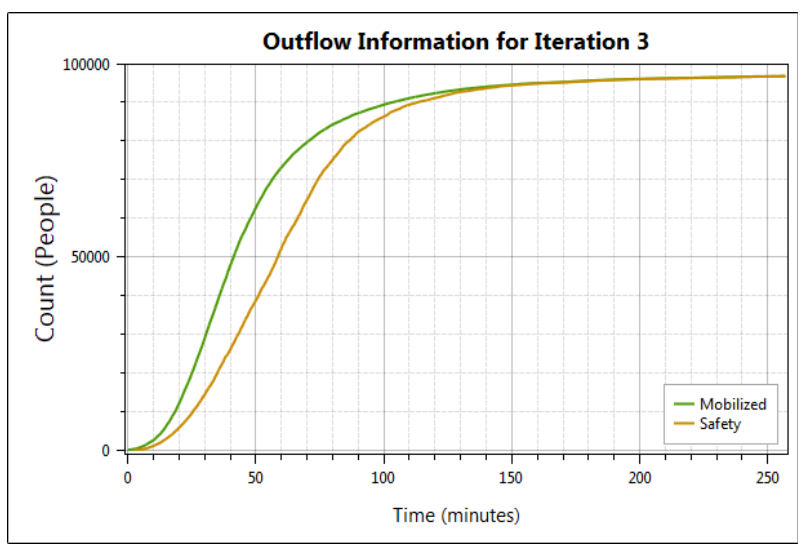

Figure 7; Results of HEC-LifeSim

\section{Concluding remarks and discussion}

In the US, mostly micro-scale dynamic modelling is used for evacuation. In the Netherlands macro scale modelling is used assuming a constant driving velocity. The assumption of such a (low) constant velocity may be too pessimistic for cases where sufficient exit capacity is available. In this cases application of dynamic model could provide further insight. However, various model inputs are needed and several input and model uncertainties could be associated with such a dynamic model.

In consequence and risk studies in the Netherlands preventive evacuation (before breaching) is considered. In the US evacuation is analysed until the arrival of floodwaters (at a certain location). During an actual emergency several uncertainties (e.g. warning, location of breaching) and environmental conditions (e.g. weather) could affect evacuation success.

In the US interaction between the evacuation process and floodwater movement is included. The question is whether this assumed / programmed type of interaction and driver behaviour will occur during real emergencies. Also, there are different definitions of safe zones. In the Netherlands locations outside the area at risk or high grounds are considered safe zones, or people are add to a shelter fraction (and so removed from the traffic model). In the US within HEC FIA safe zones re locations with less than $2 \mathrm{ft}$ of water (within affected area).

Knowledge of the time needed for the three phases of evacuation (departure, travel, exit) can be used to estimate the required level of detail. When the travel time is most significant for the total time for evacuation the importance of more detail in the departure curve is limited. When the departure time is most significant (for small areas for example) the process of departure is more significant for the total evacuation time.

The case study of Natomas shows that the time needed for travel to leave the threatened area is less than 
the time needed for departure (this departure time includes warning, diffusion and mobilization). The relation between the travel time and departure also depends on the population which has to be evacuated and the road capacity. For example for the dense populated coastal area in The Netherlands the time needed for travel (as in days) in case of a coastal flood is far longer than the time needed to departure (as in hours) [2, 3, 11].

The case study for Natomas also shows that the way the road network is used influences the time needed for travel. The Evacuation Calculator shows that only in a case of the management strategy 'nearest exit' the travel time is significant more than in the management strategies 'reference' and 'traffic management'. Also Lifesim shows a limited time needed for travel, Lifesim takes interaction between the people, road network en the flood into account to adjust route choices. More insight in the expected behaviour of the public in case of an evacuation can be used to develop evacuation strategies. When the management strategy 'nearest exit' is a realistic event based on the current risk perception of the people in Natomas and the expected route choices of these people the effectiveness of preventive evacuation can be increased by traffic management. In all cases effectiveness of evacuation for Natomas can increase when the total time for departure (warning, diffusion and mobilization) is reduced.

The realism of a specific scenario described by a model can be questioned because these models are in most cases not validated for evacuation. The realism depends on the boundary conditions of the models and the used algorithms. For example HEC-FIA assumed people to walk or drive to a nearby safe place and takes the interaction with a flood into account which results in adjustment of route choices. HIS-EC can take different forms of origin and destinations into account but people cannot change their route given traffic conditions or a flood.

The probabilistic model EvacuAid can be used to deal with knowledge of the realism (and probability) of different scenarios and developed expected values the number of people which can evacuate, estimate loss of life for different strategies for evacuation and a bandwidth. The database of evacuation scenarios EvacuAid used can be defined with macro or micro models. The evacuation scenarios, probabilities of them and mortality rates have to be based on the local circumstances. EvacuAid can also be used to define the effectiveness of measures taken the uncertainties into account.

\section{References}

1. Kolen B. (2013). Certainty of uncertainty in evacuation for threat driven responses; Principles of adaptive evacuation management for flood risk planning in the Netherlands. PhD Thesis University of Nijmegen.
2. Jonkman SN. (2007). Loss of life estimation in flood risk assessment. Theory and applications. PhD Thesis. Delft University of Technology.

3. Barendregt A, van Noortwijk JM, van der Doef M, Holterman SR. (2005). Determining the time available for evacuation of a dike-ring area by expert judgement. In Vrijling JK, Ruijgh E, Stalenberg B, Van Gelder PHAJM, Verlaan M, Zijderveld A, Waarts P (eds). International Symposium on Stochastic Hydraulics.

4. Gwynne G, Galea, ER, Owen, M, Lawrence, PJ (2002). An investigation of the aspects of occupant behaviour required for evacuation modeling. Edited by P.R. DeCicco. Vol. 2, Evacuation from fires. New York: Baywood Publishing Company, Inc., Amityville.

5. van Zuilekom KM, van Maarseveen MFAM and van der Doef MR. (2005). A Decision Support System for preventive evacuation of people. In Geo-information for disaster management, edited by Zlatanova $\mathrm{P}$, Van Oosterom, S, Fendel, EM. : Springer Berlin Heidelberg.

6. Mileti DS. Sorensen JH. (2015). A Guide to Public Alerts and Warnings for Dam and Levee Emergencies. USACE

7. Pel AJ. (2011). Transportation modelling for regional evacuations, Delft University of technology, Delft.

8. Bedford T, Cooke R. (2001). Probabilistic risk analyses: foundations and methods. p19

9. Fields, W, Bahner, C, Needham, and J, Goodell, C (2012). Dam and Levee Safety Risk Assessment - Evaluating Routing and Life Loss Estimation Using LifeSim. USSD Proceedings.

10. Bureau of reclamation (2014). RCEM Reclamation Consequence Estimating Methodology Guidelines for Estimating Life Loss for Dam Safety Risk Analysis.

11. Kolen B, Kok M, Helsloot I, Maaskant, B. (2013. EvacuAid: A Probabilistic Model to Determine the Expected Loss of Life for Different Mass Evacuation Strategies During Flood Threats. Risk Analysis, 33: 1312-1333.

12. National Academies Committee on Flood Control Alternatives in the American River Basin (NA). (1995). "The Natomas Basin." Flood risk management and the American River Basin: An evaluation. National Academic Press, Washington, DC, 166-176.

13. Jonkman SN, Maaskant B, Kolen B, Zethof M. (2013). Loss of Life, Evacuation and Emergency Management: Comparison and application to case studies in the USA. TUDelft and HKV. 